\title{
Measurements of organic gases during aerosol formation events in the boreal forest atmosphere during QUEST
}

\author{
K. Sellegri ${ }^{1}$, M. Hanke ${ }^{1}$, B. Umann ${ }^{1}$, F. Arnold ${ }^{1}$, and M. Kulmala ${ }^{2}$ \\ ${ }^{1}$ Atmospheric Physic Division, Max Planck Institute for Nuclear Physics, Heidelberg, Germany \\ ${ }^{2}$ Department of Physical Sciences, University of Helsinki, Finland
}

Received: 26 March 2004 - Published in Atmos. Chem. Phys. Discuss.: 20 August 2004

Revised: 11 January 2005 - Accepted: 25 January 2005 - Published: 8 February 2005

\begin{abstract}
Biogenic VOCs are important in the growth and possibly also in the early stages of formation of atmospheric aerosol particles. In this work, we present 10 min-time resolution measurements of organic trace gases at Hyytiälä, Finland during March 2002. The measurements were part of the project QUEST (Quantification of Aerosol Nucleation in the European Boundary Layer) and took place during a twoweek period when nucleation events occurred with various intensities nearly every day. Using a ground-based Chemical Ionization Mass Spectrometer (CIMS) instrument, the following trace gases were detected: acetone, TMA, DMA, mass $68 \mathrm{amu}$ (candidate=isoprene), monoterpenes, methyl vinyl ketone (MVK) and methacrolein (MaCR) and monoterpene oxidation products (MTOP). For all of them except for the amines, we present daily variations during different classes of nucleation events, and non-event days. BVOC oxidation products (MVK, MaCR and MTOP) show a higher ratio to the CS on event days compared to non-event days, indicating that their abundance relative to the surface of aerosol available is higher on nucleation days. Moreover, BVOC oxidation products are found to show significant correlations with the condensational sink (CS) on nucleation event days, which indicates that they are representative of less volatile organic compounds that contribute to the growth of the nucleated particles and generally secondary organic aerosol formation. Behaviors of BVOC on event and non event days are compared to the behavior of $\mathrm{CO}$.
\end{abstract}

\section{Introduction}

Organic molecules have been found to be important constituents of atmospheric aerosols in many air masses (Novakov et al., 1997; Sellegri et al., 2003), and are often present

Correspondence to: K. Sellegri

(K.Sellegri@opgc.univ-bpclemront.fr) together with sulfate and other inorganic species in a single aerosol particle (Murphy et al., 1998). However, the chemical composition of particles at an early stage of their formation (nano-particles) is still an open question, as the aerosol mass available for analysis is not sufficient. We know now that "atmospheric oxidation of biogenic hydrocarbons, such as monoterpenes, is estimated to be a significant source of global aerosol" (Yu et al., 1999), as established by several laboratory studies (Hoffmann et al., 1997; Griffin et al., 1999; Koch et al., 2000; Gao et al., 2001) and field studies (Leaitch et al., 1999; Kavouras et al., 1999). The important question related to the ability of organic gases to form secondary aerosol particles, i.e. when and how they are incorporated into the particulate phase, can be alternatively studied from the gaseous point of view.

Smog chamber experiments showed that very low organicozone reactant levels as precursor for the formation of new sub- $\mu \mathrm{m}$ aerosols were needed (Gao et al., 2001). In the boreal forest, frequent formation of new particles has been observed (Kulmala et al., 2001a), and VOCs (Volatile Organic Compounds) have been studied in relation to this new particle formation in different manners. Seasonal and diurnal variation of terpenes have been measured, using Tenax tubes (Hakola et al., 2000), emission fluxes of monoterpenes have been studied using Tenax tubes as well with a two hours resolution (Janson et al., 2001), and vertical profiles of monoterpenes have been measured using tethered balloons and adsorbent cartridges (Spirig et al., 2004). However, high time resolution measurements of terpenes and particularly of their oxidation products, which are candidates for condensation, are missing to address the possibility of organic-induced nucleation.

VOCs are released from a wide variety of sources, and their mixing ratios measured at one point can be either dominated by a remote source or, in our case, by the local biogenic source or even a local pollution source. Most VOCs react with hydroxyl radicals $(\mathrm{OH})$; some can be photolyzed,

(c) 2005 Author(s). This work is licensed under a Creative Commons License. 
react with ozone, or at night with nitrate radicals $\left(\mathrm{NO}_{3}\right)$. In this work, we present measurements of organic gases with a high time resolution on the Hyytiälä SMEAR II station site, using a ground-based CIMS instrument developed by MPI$\mathrm{K}$ Heidelberg. Both the fast time response and the extended periods of measurements allow the study of the variability of mixing ratios, hence giving indications on the proximity of their sources/sinks. This paper aims to present the atmospheric time evolution of volatile organic gases in relation to nucleation events. Dimethylamine (DMA), trimethylamine (TMA), the sum of Methyl Vinyl Ketone (MVK) and methacrolein (MaCR) and MTOP are studied as organic candidates, or representative of organic candidates for nucleation and/or growth of the newly formed particles. Mass $68 \mathrm{amu}$ (candidate=isoprene) and the sum of monoterpenes are also reported as precursors of condensing species, and $\mathrm{CO}$ and acetone are reported as indicators of organic degradation products as a whole.

\section{Site and sampling characteristics}

\subsection{Site characteristics}

The SMEAR II experimental station (Station for Measuring Forest Ecosystem-Atmosphere Relations) located in Hyytiälä, southern Finland $\left(61^{\circ} 51^{\circ} \mathrm{N}, 24^{\circ} 17 \mathrm{E}, 181 \mathrm{~m}\right.$ above sea level) is representative of the boreal coniferous forest. Meteorological parameters including wind speed and direction, temperature, pressure, relative humidity, and global radiation are measured at different levels above the ground, using a 72-m-high mast on a permanent basis (Kulmala et al., 2001a). Gas measurements using the CIMS instrument presented in this work have been performed from a container located in the vicinity of the SMEAR II station, i.e. $50 \mathrm{~m}$ southwest, at $2.5 \mathrm{~m}$ above the ground. The comparison of water vapor measurements obtained with the CIMS set up with the water vapor measured at the station $(4.2 \mathrm{~m})$ show excellent agreement (less than 5\% disagreement). Thus our trace gas measurements can be considered to have taken place in the same air masses as the SMEAR II station measurements. Meteorological conditions together with aerosol size distributions over the measurement period are summarized Fig. 1 .

Data presented in this paper are based on samplings achieved during 12 days: from 17 to 29 March 2001.

\subsection{Instrumental}

The Chemical Ionization Mass Spectrometer (CIMS) method is based on ion-molecule reactions involving gaseous ions and atmospheric trace gas molecules. An atmospheric gas $\mathrm{X}$ which has a proton affinity larger than that of $\mathrm{H}_{2} \mathrm{O}$ $\left(166.5 \mathrm{kcal} \mathrm{mol}^{-1}\right)$ reacts in the flow tube reactor with the re- actant ions $\mathrm{H}_{3} \mathrm{O}^{+}\left(\mathrm{H}_{2} \mathrm{O}\right)_{n}$ (produced by an external high frequency glow-discharge ion source) via:

$$
\mathrm{H}_{3} \mathrm{O}^{+}\left(\mathrm{H}_{2} \mathrm{O}\right)_{n}+\mathrm{X} \rightarrow \mathrm{HX}^{+}\left(\mathrm{H}_{2} \mathrm{O}\right)_{n}+\mathrm{H}_{2} \mathrm{O}
$$

The residence time in the flow tube reactor is $3.2 \mathrm{~s}$, allowing some fraction of $\mathrm{X}$ to react during traveling in the flow tube reactor. The X-concentration is determined. by measuring the abundance ratio of product and reactant ions. The scanning time for the mass range 1 to $200 \mathrm{amu}$ is $40 \mathrm{~ms}$.

Because the detection of organic gases with the CIMS technique used here allows only to determine the mass number of $\mathrm{X}$, the exact chemical identification of $\mathrm{X}$ remains somewhat ambiguous (i.e. several different compounds might have the same mass), mixing ratios presented in this work, namely acetone, DMA, TMA, isoprene, MVK+MaCR, monoterpenes and MTOP are only the most likely candidates. In fact, at mass 68 amu+its hydrates, isoprene is detected together with another compound, which, from its daily variation, is probably from biogenic origin. Holzinger et al. (2005) have recently observed with the PTRMS technique some unidentified biogenic compound above a pine forest at masses $105 \mathrm{amu}$, which could contribute to our isoprene mixing ratios when hydrated. Hence, Mass $68 \mathrm{amu}$ and hydrates will be referred to as isoprene+compound X. Detailed analytical procedures, assumptions, calibrations and measurement problems are discussed in Sellegri et al. (2005)

The routine measurements performed with commercial instruments at the SMEAR II station such as the meteorological data and $\mathrm{CO}$ concentrations are reported, as well as the measurements relevant to aerosol nucleation events performed as part of the QUEST campaign, such as total number concentrations, and Condensational Sink (CS, calculated from the surface of particles available for condensation) (Kulmala et al., 2001b).

\section{Results}

3.1 Detected species relevant to particle nucleation in the boreal forest atmosphere

Isoprene and the sum of monoterpenes could be detected by CIMS, as well as, for the first time with this technique, some of their oxidation products with a $10 \mathrm{~min}$ resolution. We have to be cautious with isoprene+compound $\mathrm{X}$ concentrations, as the level of the mixing ratios and diurnal variations are not similar to what is usually found at the SMEAR II station for isoprene. MVK and MaCR, both oxidation products from isoprene, and pinonaldehyde (major oxidation product of $\alpha$ pinene), and other monoterpene oxidation products (hereafter referred as MTOP), were identified and measured with a 10 min resolution as well. Although monoteprenes, MTOP and MVK+MaCR calibrations could not be performed during the QUEST campaign, the CIMS instrument provides 


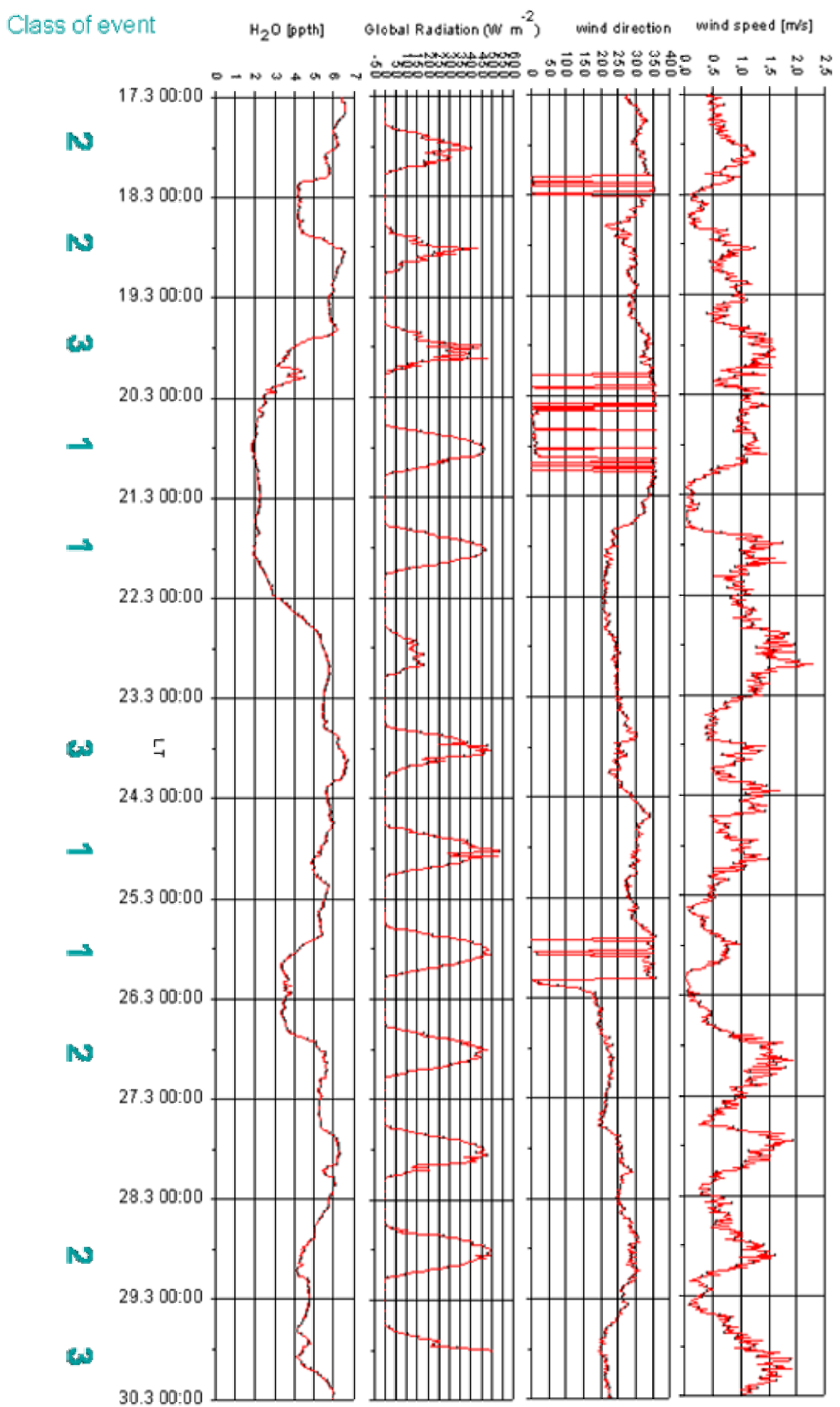

Fig. 1. Meteorological conditions (temperature, $\mathrm{H}_{2} \mathrm{O}$, wind speed and direction, radiation) during the two weeks measurement period. During this period, particle formation event occurred every day but on the 22 and 27 March. Particle formation events are classified into three classes according to their strength, with decreasing strength from 1 to 3. 


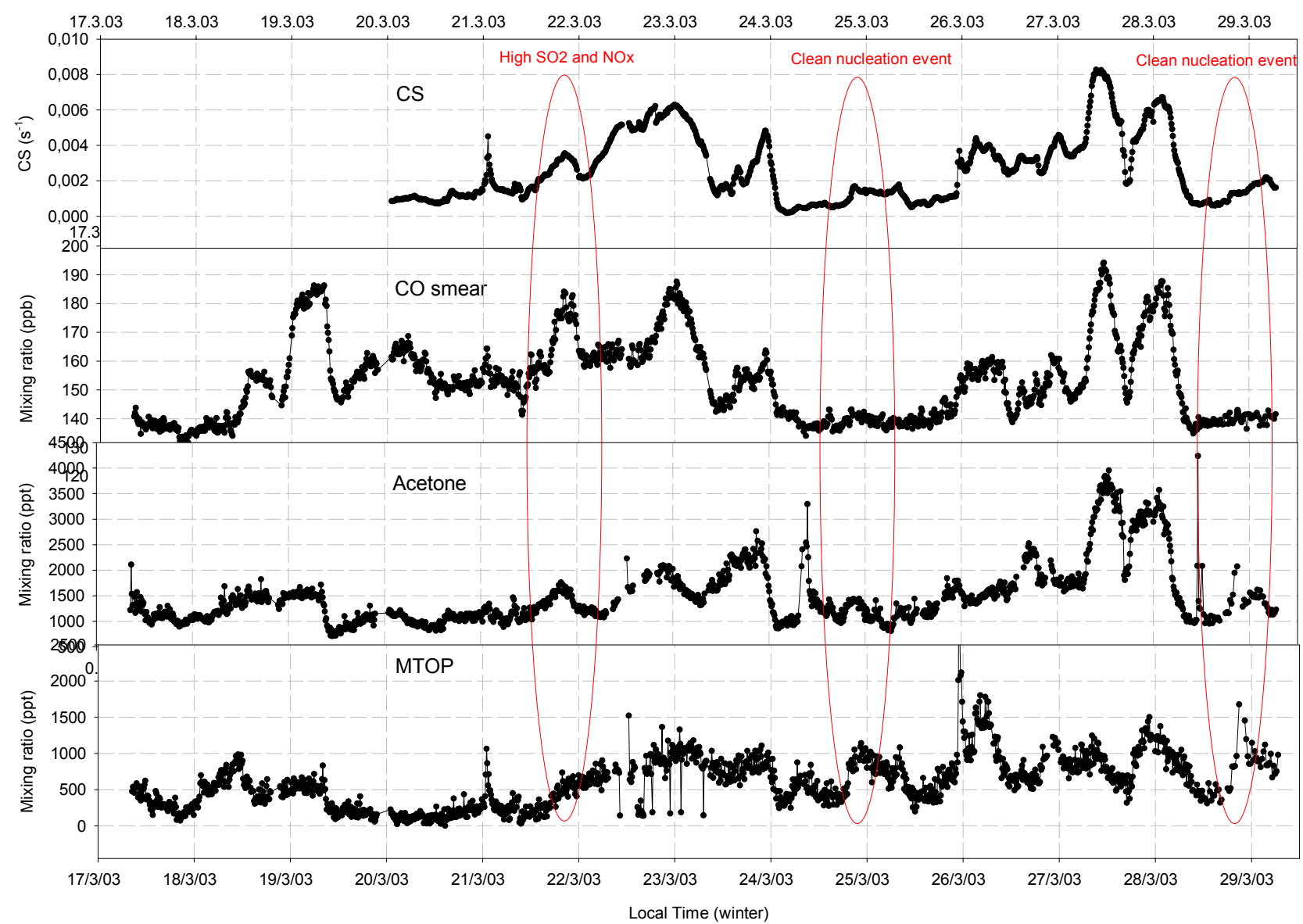

Fig. 2. Condensational sink (calculated from the surface of particles available for condensation), CO, acetone and MTOP versus local time. A co-variation is observed between most organic species (not all shown) and the condensational sink, in more or less agreement depending on the air mass type.

lower limits of mixing ratios (because all artifacts are leading to an underestimation of the concentrations: wall losses, water content dependant back reactions, use of the collision rate reaction constant) (Sellegri et al., 2005).

Pinenes are among the most abundant monoterpenes, and isoprene, $\alpha$-pinene and $\Delta^{3}$-carene were found to be the most abundant compounds among light hydrocarbon and monoterpene in the boreal forest (Hakola et al., 2000; Spanke et al., 2001). Our concentrations during the QUEST campaign ranged between 90 and $185 \mathrm{pptv}$ ( 25 and 75iles) for isoprene+compound $\mathrm{X}$, and 190 and $400 \mathrm{pptv}$ for the sum of monoterpenes. Those concentrations are higher than previous measurements on the same site for isoprene alone (Hakola et al., 2000; Spirig et al., 2004). The sum of monoterpenes has been detected above the boreal forest canopy with concentrations of $360 \mathrm{ppt}$ (Spanke et al., 2001), which lies within the range of our measurements.

Ozonolysis of $\alpha$ - and $\beta$-pinene can give aerosol carbon yields of $14-18 \%$ and oxidation of $\alpha$ - and $\beta$-pinene by $\mathrm{OH}$ can give carbon yields of 40-60\% (Hatakeyama et al., 1989 and 1991). According to the work of Yu et al. (1999), the major oxidation products of the reaction between $\mathrm{O}_{3}$ and pinene or carene are usually aldehydes (pinonaldehyde for $\alpha$-pinene and caronaldehyde for carene), showing that they are good tracers for the oxidation product of terpenes. It is those aldehydes which are detected by CIMS on mass $168 \mathrm{amu}$. Pinonaldehyde has been detected in the gas and aerosol phase after introduction of pinene and $\mathrm{O}_{3}$ in a smog chamber, showing that it is a condensable gas (Yu et al. 1999, Kavouras et al., 1999). Although the partionning of pinonaldehyde is only $1 \%$ in the aerosol phase, this compound is also representative for the other terpene oxidation products which have lower vapor pressures and can not be detected by the CIMS method (mostly dicarboxylic acids, Gao et al., 2001). Moreover, MTOP mixing ratios measured by CIMS in Hyytiälä were in the range 320-840 pptv, hence it is the second most abundant compound family measured with CIMS after acetone (Sellegri et al., 2005). Pinonaldehyde has been measured on the Hyytiälä site with maximum concentrations of $140 \mathrm{ppt}$. Other monoterpene oxidation products may comprise a large 

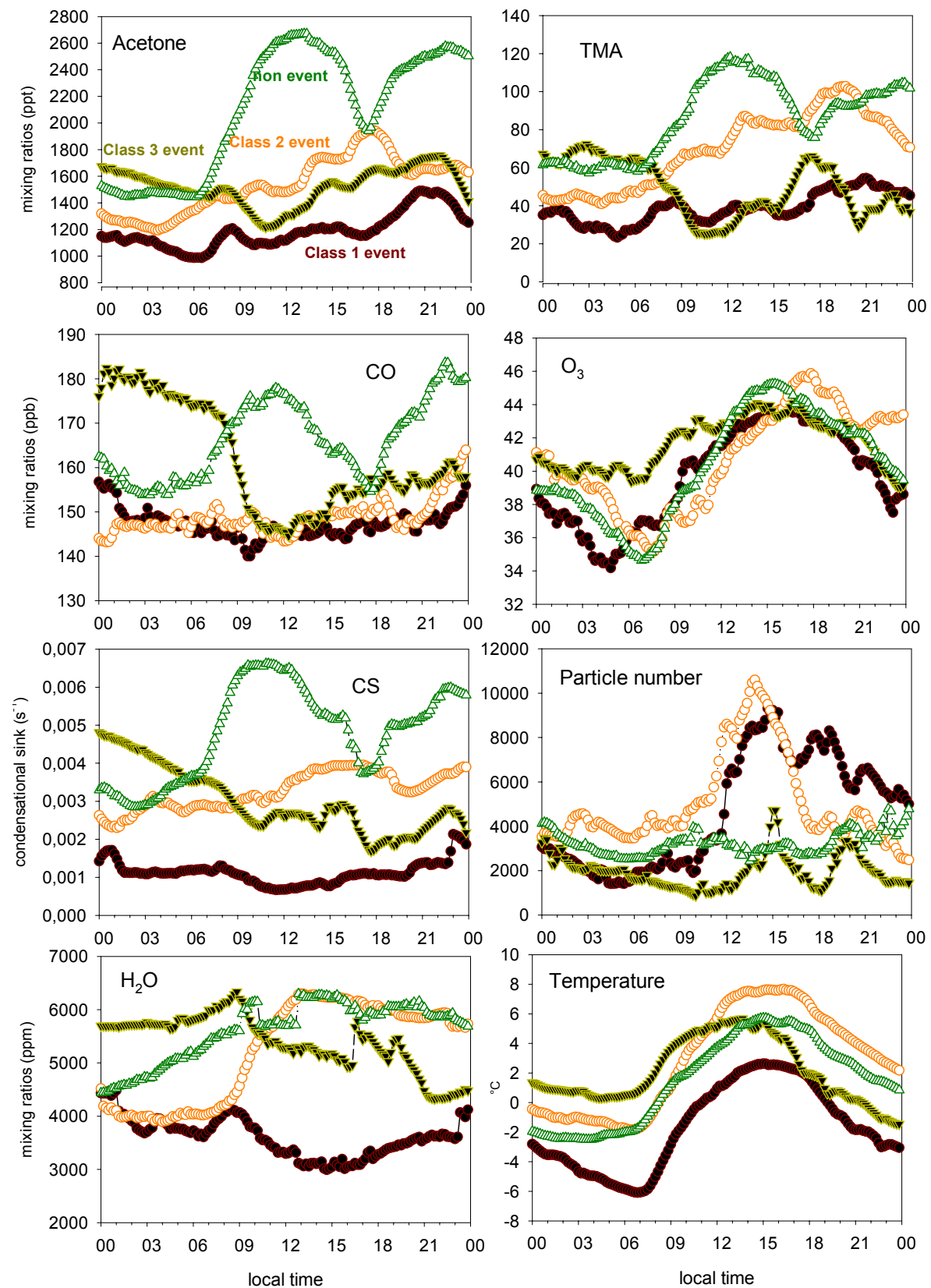

Fig. 3. Daily median concentrations of organic gases, ozone, $\mathrm{H}_{2} \mathrm{O}$, particle number, and CS class 1 event days (brown), class 2 (orange), class 3 ( yellow) and non-event days (green). The On non-event days, the condensational sink and most organic gases concentrations are higher than on event days.

part of the MTOP that we measured with our technique but also, it is a considerable advantage to measure them online, compared to the classic cartridge measurement type which might imply several pre-analysis artifacts. The sum of $\mathrm{MVK}+\mathrm{MaCR}$ was measured with ratios varying between 100 and 240 pptv (25 and 75iles), in agreement with previous measurement performed on the Hyytiälä site (Hakola et al., 2003).
Dimethyl amine (DMA) and trimethyl amine (TMA) have also been found in atmospheric aerosols, and especially in aerosols with small sizes (Kulmala et al., 2001a; Sellegri, unpublished results). Thus they are integrated in the condensed phase either by dry condensation, either by dissolution in partially liquefied aerosols at higher relative humidity. DMA and TMA could be measured with CIMS for the first time. Vapor pressures for these two species are relatively 

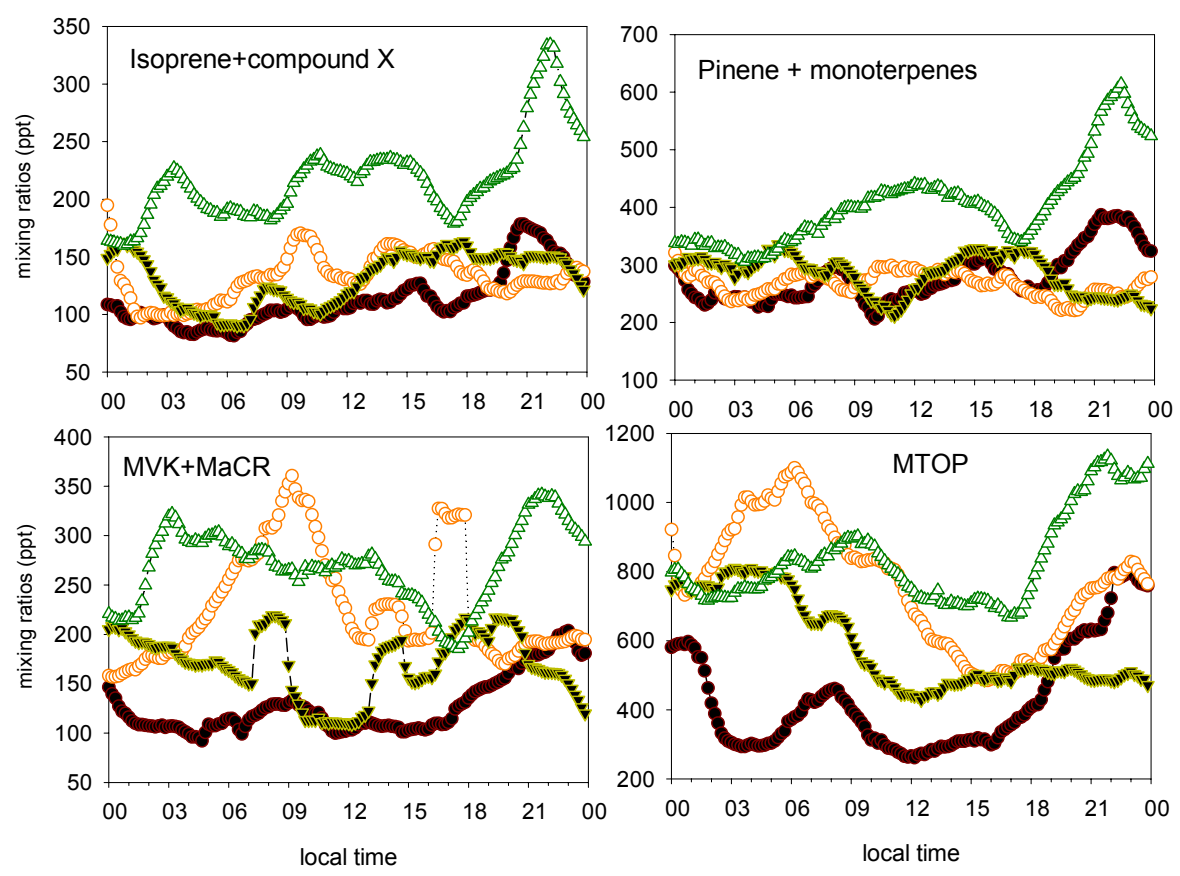

Fig. 3. Continued.

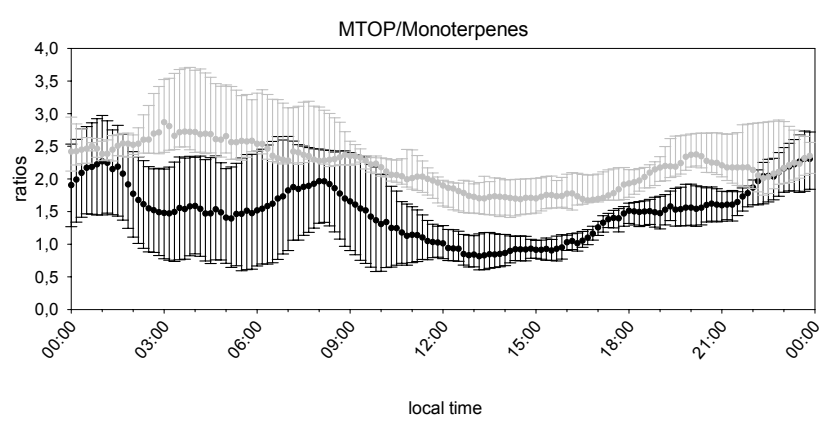

Fig. 4. Daily median ratios and MTOP/monoterpenes during class 1 event days (black) and during all other cases (grey). Error bars are calculated from percentiles $25 \%$ and $75 \%$. The ratios are in favor of the Monoterpenes Oxidation Products during class1 nucleation days compared to other cases.

high (respectively 203 and $215 \mathrm{kPa} \mathrm{mol}^{-1}$ ), hence their contribution to nucleation is unlikely. However, DMA and TMA are highly soluble; a wet deposition on aerosol surfaces is expected. DMA mixing ratios are below the detection limit of 32 pptv, and TMA mixing ratios vary between 34 and $80 \mathrm{pptv}$. Both compounds are either poorly produced or efficiently removed from the boreal forest atmosphere. DMA and TMA are derivative of ammonia in which two or three of the hydrogen have been replaced by methyl groups. In the presence of TMA, measuring DMA mixing ratio lower than the detection limit would indicate that it has been produced and destructed by an efficient sink. Although DMA and TMA can not be excluded from condensing on newly formed particles during nucleation events, the low mixing ratios they showed during the campaign do not allow us to study further their times series.

\section{Time series and median daily variations for event and non-event days}

For a large time scale overview of the evolution of mixing ratios during the measurement campaign, we applied a 9 data point box smoothing procedure to the 10 min resolution mixing ratios, and plotted one representative of the biogenic oxidation products (MTOP), together with acetone as a reference of the CIMS technique, $\mathrm{CO}$ as an reference of an independent gas measurement and the condensation sink (Fig. 2).

The beginning of the measurement period is characterized by northern clean air masses, until 21 March (Fig. 1, and also air mass back trajectories, low $\mathrm{CO}, \mathrm{NO}$ and $\mathrm{NO}_{\mathrm{x}}$ levels, Keronen, P., personal communication). Particle formation occurred every day under these clean-northern conditions (Period 1). West-Southern winds follow this period, with higher levels of pollution until the 23. Nucleation is not observed on the 22 and very weak on the 23 (Period 2). From the 23 to the 26, Northern winds favoring nucleation are observed again, similar to the Period 1 , even though the air mass origin is West. On the 27, air masses are similar to the Period 2.

From 17 to 29 March, 10 nucleation events occurred (every day but for the 22 and 27 March). Nucleation events 

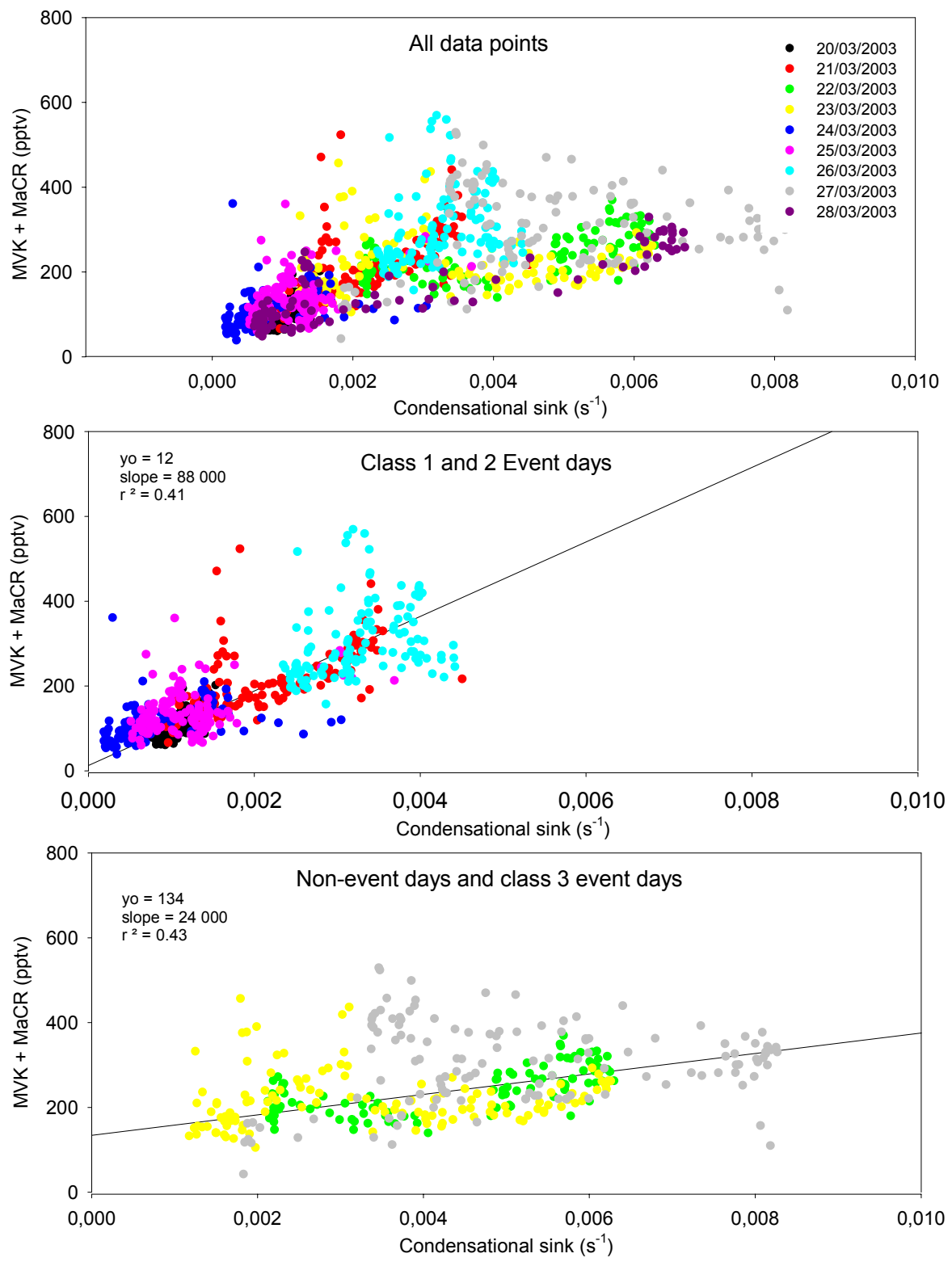

Fig. 5. (a) Correlations between MVK+MaCR and the condensational sink for all data points (upper panel), for class 1 and class 2 event days (middle panel), and for class 3 and non event days (lower panel). (b) Correlations between monoterpenes oxidation products (MTOP) and the condensational sink. For both oxidized organic compounds, correlations are significant on Class $1+2$ event days but not on class 3 and non-event days (c) Correlations between CO and the condensational sink. Significant correlations are observed during non-event days.

were of various intensities and have been classified into three classes, from class 1 events (high intensity) to class 3 events (poor intensity) (Fig. 1, M. Dal Maso, personal communication). A median daily variation is calculated for each of the event class and for non-event class (Fig. 3). 28 March was excluded, as part of the day was still non-event. On class 1 and class 2 event days, we observe a steep increase of particle number (from 2000 to $10000 \mathrm{~cm}^{-3}$ ) due to nucleation from 10:00 to 14:00 (LT), followed by an increase of the CS generally showing a maximum during the night. On non-event days and class 3 event days, the total particle number stays rather stable (between 1000 and $4500 \# \mathrm{~cm}^{-3}$ ). Going from class 1 to class 3 , the mid-day peak of particle number is decreasing, while for all cases (all class event and non-event), a secondary late evening-early night peak is observed with the similar intensities. On both event and non-event days, ozone has a very similar daily pattern. Class 1 event days are characterized by a lower amount of water vapor and a lower temperature than other classes of event days and than non-event days. Concentrations of all organic gases, as well as the CS, 

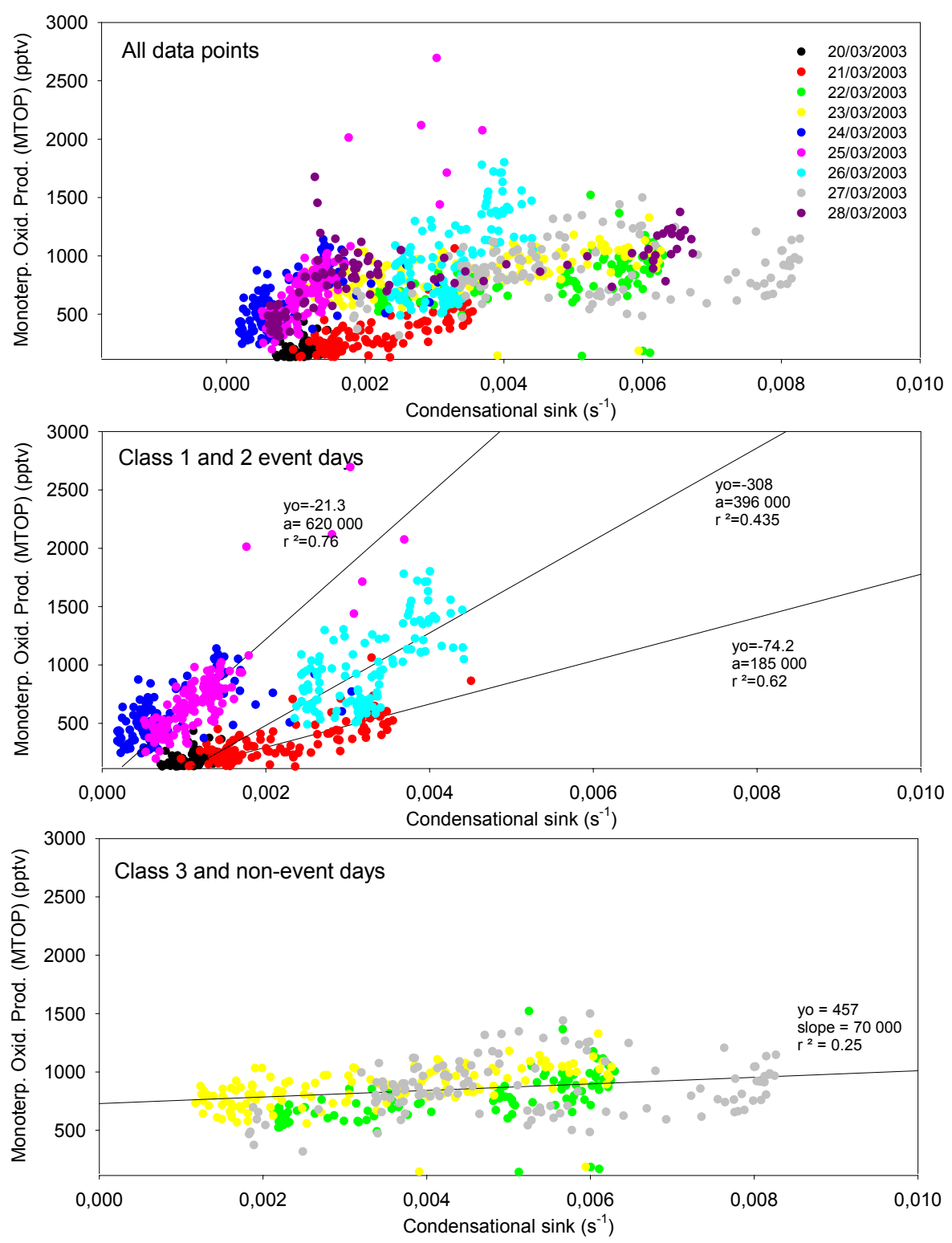

Fig. 5b. Continued.

are higher on non-event days. In all cases (event and nonevent days), acetone, isoprene, monoterpenes, MTOP and MVK+MaCR show the same pattern as the CS: a main night peak showing a maximum between 21:00 and midnight, and a mid-day peak, more or less pronounced and more or less early, depending on the species. For class 1, class 2 and class 3 event days, the dawn peak is emphasized for the terpene oxidation products (MVK+MaCR and MTOP).

Variations of MTOPs relative to their precursors can be studied (Fig. 4). On class 1 nucleation days, MTOPs are either less produced, or more condensing/destroyed on nucleation days as shown by the MTOP/Monoterpene ratios. Ratios between monoterpenes and their oxidation products are in favor of the oxidation product on non-event days compared to the event days. This "depletion" of MTOP during class 1 nucleation days can be related to a higher light related reactivity (class 1 event days are overall sunny, class 2, 3 and non event days are overall more cloudy, and for example pinonaldehyde has a higher $\mathrm{OH}$ reactivity compared to monoterpenes such as pinene, Glasius et al., 1997). But also, the "depletion" of MTOP could indicate that, in comparison to the non-condensing terpenes, their sink by condensation is higher on class 1 nucleation days. 

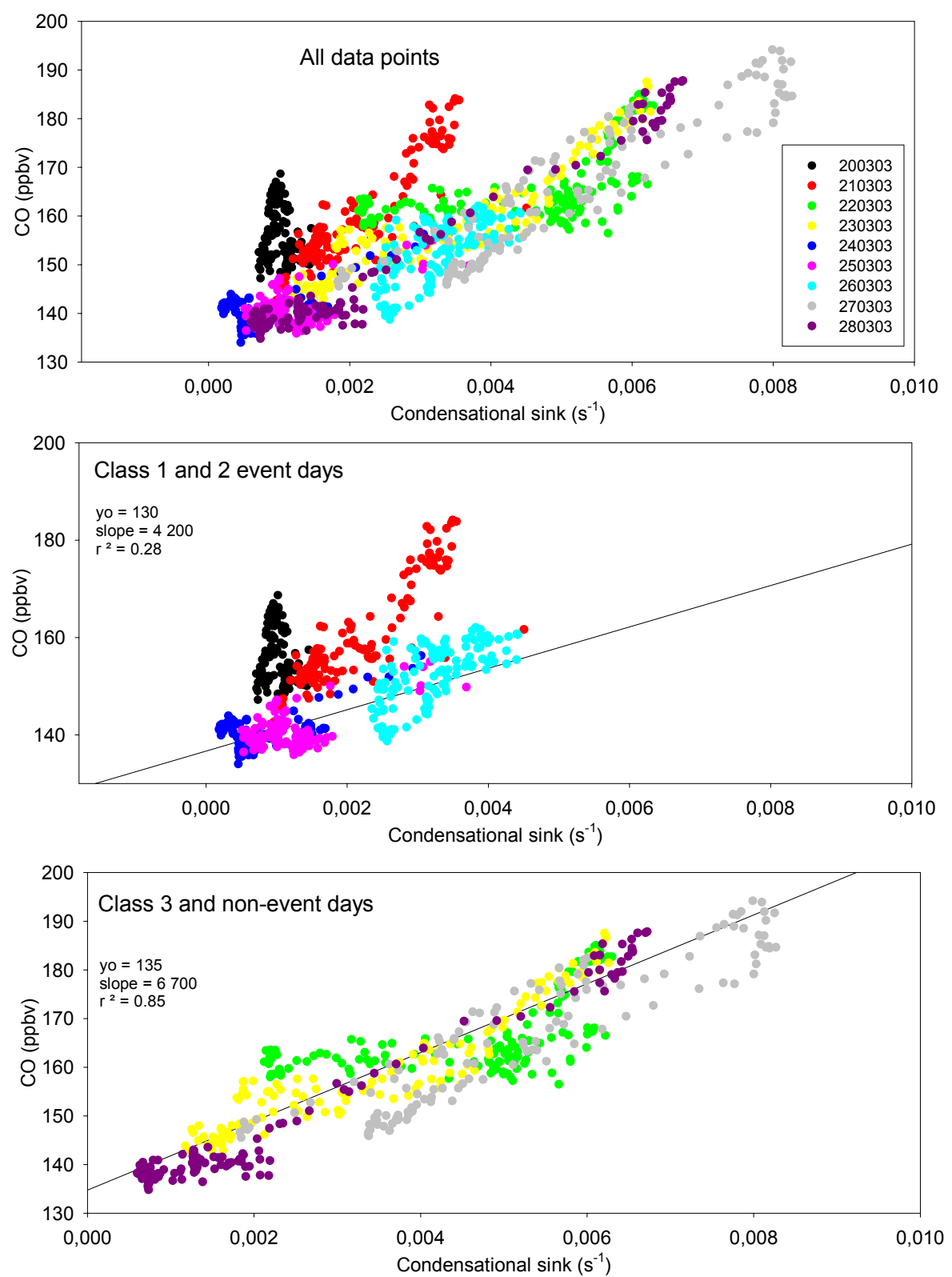

Fig. 5c. Continued.

\subsection{Correlations during event and non-event days}

We mentioned in the previous section that both VOCs and the CS had a similar daily pattern. Covariance of VOC mixing ratios and CS could indicate a possible cause-to-consequence link between VOCs and CS variations, i.e. VOCs are likely to condense on nucleated particle and participate to their growth to sizes relevant for $\mathrm{CCN}$ and radiative properties. If this is the case, obviously, the organics measured by CIMS are not consumed efficiently by the condensation process, although it is difficult to conclude on the sink without estimating what the source term of these compounds are. In order to overcome this problem, we will hereafter study the event to nonevent correlations between VOC and the condensational sink.
Day by day correlation plots (Figs. 5a to c) show that the organic-to-CS ratio for class 1 and 2 event days is very different from the non-event and poor event days (class 3) ratio. While the MTOP mixing ratios show little variations with CS changes during non-event days, the increase MTOP/CS is 3 to 4 times higher for the event days. During clean event days, concentrations of oxidized organics significantly increase in parallel to the growth of particles freshly nucleated. Marti et al. (1997) have previously found that calculated oxidized organics were correlated to the CS in a remote continental site. MVK+MaCR, is also increasing with the condensational sink. It is interesting to note that for the $28 \mathrm{March}$, for which part of the day has the same characteristics as the 


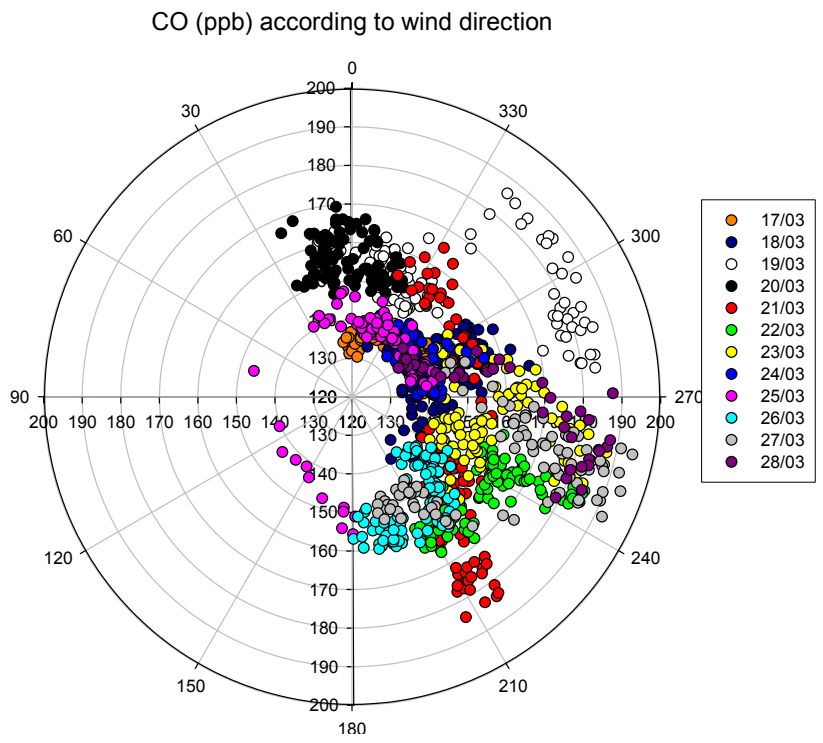

Fig. 6. CO mixing ratios as a function of wind direction.

non-event 27 March and the other part of the day has the same characteristics as the 29 (event), MTOP/CS shows a mixture of event and non-event behavior (Fig. 5b). Although the representatives of oxidized organics are measured with atmospheric mixing ratios lower during event days than nonevent days, their ratio to the condensational sink are higher on event days. Hence oxidized organics are, relatively to the condensing surface available, 1) more abundant on nucleation days and 2) increasing as the condensational sink is increasing (i.e. as the particles grow).

$\mathrm{CO}$ mixing ratios are also correlated to the condensational sink (Fig. 5c). However, we observe that $\mathrm{CO}$ is poorly linked to the CS increase on clean nucleation day (except on the the 21 March, which was more polluted), while it is significantly correlated to the CS non_event days. Higher mixing ratios of $\mathrm{CO}$ are advected at the same time than the large accumulation mode representative of more polluted air masses.

On polluted nucleation events, both $\mathrm{CO}$ and oxidized biogenic organics seemed to be responsible for the increase of the condensational sink (on the 21,26). Oxidation products of terpenes have been previously found to be correlated to $\mathrm{CO}$ above a pine plantation (Spaulding et al., 2003) and $40 \%$ of the estimated total emission of $\mathrm{CO}$ from the oxidation of natural hydrocarbons is accounted by oxidation of terpenes (Hatakeyama et al., 1991). However, the oxidation of biogenic organics would be very large in order to explain several tens of ppb of $\mathrm{CO}$. Hence the influence of the dynamics of the atmosphere is more likely. This is confirmed by the fact that high CO levels observed on the 21 and 26 are found for south-eastern wind, probably representative of local pollution (Fig. 6).

On Fig. 7, oxidized oragnics/CS ratio daily variation are shown for class 1 and 2 events on one hand, and class 3 and non-event days on another hand. The MTOP/CS ratio is rather stable through the diurnal variation and nighttime maxima are not observed; there is a tendency of an early morning to mid-day increase of $\mathrm{MVK}+\mathrm{MaCR} / \mathrm{CS}$ during event days.

\section{Discussion}

Results from the BIOFOR campaign (BIOgeic aerosol FORmation in the boreal forest), which took place on the Hyytiälä sampling site during spring in the years 1998 and 1999 gave little support for the hypothesis that terpene oxidation products were the precursors to the observed new particle formation. They were however not excluded from taking an active part in the growth of the new particles (Janson et al. 2001). The reasons for these conclusions were that (1) SOC (Secondary Organic compounds) were higher at night when no nucleation occurred, and (2) SOC were not significantly higher during event days compared to non-event days.

There are similarities and discrepancies between our data set and the data set from the BIOFOR campaign:

- Mixing ratios were of similar order of magnitude during both field measurement campaigns

- In both field measurement campaigns terpenes and their oxidation products have been found to be higher at night with a maximum between 21:00 and midnight.

- While a poorly significant enhancement of monoterpenes and of the calculated source terms for secondary organic compounds were found during event days compared to non-event days during BIOFOR, our QUEST data revealed an enhancement of organic compounds including terpenes during non-event days compared to event days.

Together with the fact that a strong correlation is found between the CS and biogenic organic compounds, our observations would lead to the same conclusion as during BIOFOR: a condensing rather than nucleating role of organics.

However, the parameter SOC/CS might be of higher significance to the nucleation processes than the SOC mixing ratio alone. Then, based on the fact that the SOC/CS ratios are higher on event days than on non-event days, and that monoterpene oxidation products measured by CIMS are representative of SOC of lower vapor pressure (hence not detected by CIMS, i.e. diacids), we can not exclude organics from being candidates for the new particle formation. Actually, among the MTOPs measured with CIMS, some have a relatively low vapor pressure. For example, pinonaldehyde has a vapor pressure of $4.4 \times 10^{-2} \mathrm{kPa}$ at $25^{\circ} \mathrm{C}$, to be compared with the $2.7 \times 10^{-6}$ at $25^{\circ} \mathrm{C}$ of sulfuric acid. Since MTOP were found with mixing ratios up to $10^{4}$ higher than sulfuric acid mixing ratios (between 40 and 

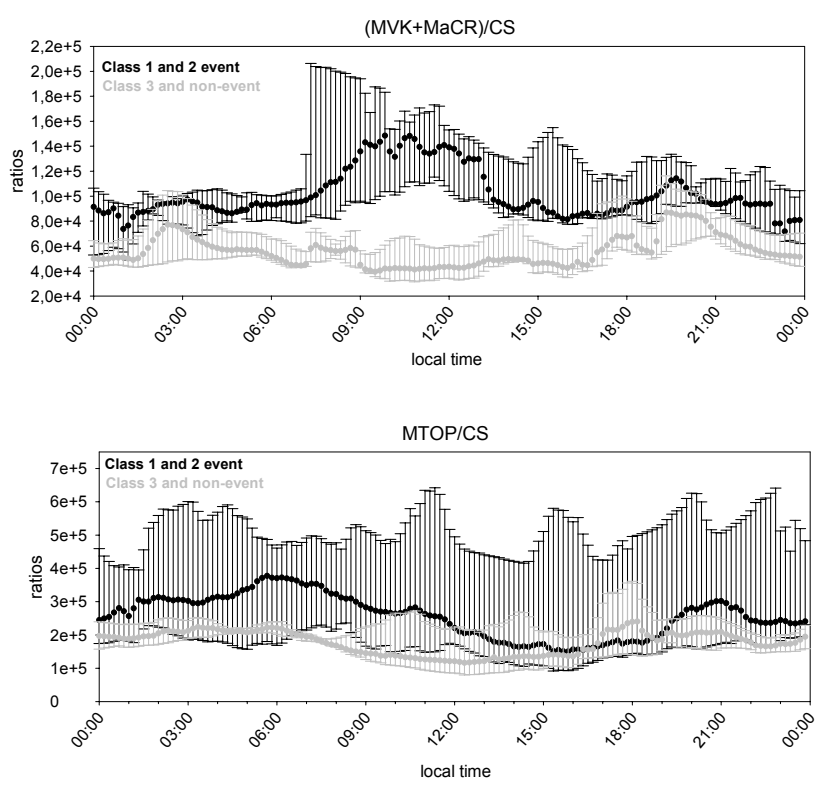

Fig. 7. Daily median ratios (MVK+MaCR)/CS (upper panel) and MTOP/CS (lower panel) during class 1 and 2 event days (black) and class 3 and non-event days (grey). Error bars are calculated from percentiles $25 \%$ and $75 \%$. The ratio of MVK+MaCR to the condensational sink is higher on class 1 and 2 event days, and maximum during the day.

$600 \mathrm{ppq}\left(10^{-15} \mathrm{~mol} \mathrm{~mol}^{-1}\right)$, F. Arnold, personal communication), and pinonaldehyde is the most abundant representative of MTOP, it is probable that it condenses at a some stage of particle formation. In fact, the comparison of TOP/CS behavior between MVK+MaCR and MTOP shows a difference that could be due to an additional sink by condensation for the MTOP, compared to MVK+MaCR. Indeed, correlation plot for event days of MTOP vs. CS show negative MTOP mixing ratios when extrapoling to low CS, which could be an indication of the condensing process at the very early stage of particle formation.

\section{Summary and conclusions}

Measurements of volatile organic gases were performed with a $10 \mathrm{~min}$ resolution in the boreal forest atmosphere, using a ground-based CIMS instrument, as part of the QUEST project. Acetone, TMA, DMA, isoprene, monoterpenes, MVK+MaCR and pinonaldehyde were selected to study the relationship between biogenic gaseous emissions and nucleation and growth of new particles.

Isoprene+compound $\mathrm{X}$, monoterpenes, $\mathrm{MVK}+\mathrm{MaCR}$ and MTOP are measured with a higher mixing ratio at night than during the day (maximum between 21:00 and midnight). The onset of a nocturnal stable surface layer is presumably trapping the night-produced VOCs (but also acetone and $\mathrm{CO}$ ). These five biogenic organic species show more or less signif- icant correlation with the condensational sink (CS) depending on the type of nucleation event, indicating that particle growth is probably not always due to the same species depending on the air mass type.

Best correlations are observed for the oxidized biogenic compounds (MTOP and MVK+MaCR). MTOP and $\mathrm{MVK}+\mathrm{MaCR}$ are significantly correlated to the CS on event days while not during non event days. Mixing ratios of MTOP increase with CS by a factor 3 to 4 compared to nonevent days. Moreover, the ratio of oxidized biogenic organics to the CS is higher on event days than on non-event days. If the amount of condensing gas, corrected from the condensing surface available is indicative of the probability of nucleation, then this probability is higher on nucleation days.

Correlations are also observed between $\mathrm{CO}$ and the CS, but on non-event days, indicating an advection of both high $\mathrm{CO}$ mixing ratios and a large accumulation mode (with high $\mathrm{CS}$ ) representative of polluted air masses.

As a whole, the sum of the MTOP analyzed with the CIMS method is not consumed efficiently by the condensation process, i.e. their source is higher than their sink. However, the MTOP mixing ratios measured by CIMS in Hyytiälä were in the range 320-840 pptv, which makes MTOP the second most abundant compounds measured with CIMS after acetone, and, considering the low vapor pressure of some of them (such as pinonaldehyde), possible candidates for condensation at an early stage of the new particles formation.

Amines were measured with the lowest mixing ratios, presumably because of their high solubility and high reactivity. The low concentrations of DMA and TMA prevented us from a reliable daily variability study and work must be continued to lower the detection limit of such species with the CIMS method.

Acknowledgements. This work was financed by the QUEST project, funded by the European Community. The authors wish to thank R. Janson for fruitful discussions.

Edited by: K. Hämeri

\section{References}

Gao, S., Hegg, D. A., Frick, G., Caffrey, P. F., Pasternack, L., Cantrell, C., Sullivan, W., Ambrusko, J., Albrechcinski, T., and Kirchstetter, T. W.: Experimental and modeling studies of secondary organic aerosol formation and some applications to the marine boundary layer, J. Geophys. Res., 106, 27 619-27 634, 2001.

Glasius, M., Calogirou, A., Jensen, N. R., Hjorth, J., and Nielsen, C. J.: Kinetic study of gas-phase reactions of pinonaldehyde and structurally related compounds, Int. J. Chem. Kin., 29, 527-533, 1997.

Griffin, R. J., Cocker, D. R., Flagan, R. C., and Seinfeld, J. H.: Organic aerosol formation from the oxidation of biogenic hydrocarbon, J. Geophys. Res., 104, 3555-3568, 1999. 
Hakola, H., Laurina, T., Rinne, J., and Puhto, K.: The ambient concentrations of biogenic hydrocarbons at a northern European, boreal site, Atmos. Environ., 34, 4971-4982, 2000.

Hakola, H., Tarvainen, V., Laurina, T., Hiltunen, V., Hellen, H., and Keronen, P.: Seasonal variation of VOC concentrations above a boreal coniferous forest, Atmos. Environ., 37, 1623-1634, 2003.

Hatakeyama, S., Izumi, K., Fukuyama, T., and Akimoto, H.: Reactions of ozone with $\alpha$-pinene and $\beta$-pinene in air: Yields of gaseous and particulate products, J. Geophys. Res., 94, 13013$13024,1989$.

Hatakeyama, S., Izumi, K., Fukuyama, T., Akimoto, H., and Washida, N.: Reactions of $\mathrm{OH}$ with $\alpha$-pinene and $\beta$-pinene in air: Estimate of global CO production from the atmospheric oxidatoin of terpenes, J. Geophys. Res., 96, 947-958, 1991.

Hoffman, T., Bandur, R., Marggraf, U., and Lindsheid, M.: Molecular composition of organic aerosols formed in the $\alpha$-pinene $/ \mathrm{O}_{3}$ reaction: Implications for new particle formation process, J. Geophys. Res., 103, 25 569-26 578, 1998.

Holzinger, R., Lee, A., Paw, K. T., and Goldstein, A. H.: Observation of oxidation products above a forest imply biogenic emissions of very reactive compound, Atmos. Chem. Phys., 5, 67-75, 2005 ,

\section{SRef-ID: 1680-7324/acp/2005-5-67.}

Janson, R., Rosman, K., Karlsson, A., and Hansson, H. C.: Biogenic emissions and gaseous precursors to forest aerosols, Tellus B, 53, 423-440, 2001.

Kavouras, I., Mihalopoulos, N., and Stephanou, E.: Secondary organic aerosol formation vs primary organic aerosol emission: In situ evidence for the chemical coupling between monoterpene acidic photooxidation products and new particle formation over forests, Envir. Sci. Technol., 33, 1028-1037, 1999.

Koch, S., Winterhalter, R., Uherek, E., Kolloff, A., Neeb, P., and Moortgat, G.: Formation of new particles in the gas-phase ozonolysis of monoterpenes, Atmos. Environ., 34, 4031-4042, 2000.

Korhonen, P., Kulmala, M., Laaksonen, A., Viisanen, Y., McGraw, R., and Seinfeld, J. H.: Ternary nucleation of H2SO4, NH3, and $\mathrm{H} 2 \mathrm{O}$ in the atmosphere, J. Geophys. Res., 104, 26349-26353, 1999.

Kulmala, M., Hameri, K., Aalto, P. P., Makela, J. M., Pirjola, L., Nilsson, D., Buzorius, G., Rannik, U., Dal Maso, M., Seidl, W., Hoffman, T., Janson, R., Hansson, H.-C., Viisanen, Y., Laaksonen, A., and O'Dowd, C.: Overview of the international project on biogenic aerosol formation in the boreal forest (BIOFOR), Tellus 53B, 324-343, 2001a.

Kulmala, M., Dal Maso, M., Makela, J. M., Pirjola, L., Vakeva, M., Aalto, P., Miikkulainen, P., Hameri, K., and O'Dowd, C. D.: On the formation, growth and composition of nucleation mode particles, Tellus 53B, 479-490, 2001 b.
Leaitch, W. R., Bottenheim, J. W., Biesenthal, T. A., Li, S. M., Liu, P. S. K., Asalian, K., Dryfhout-Clark, H., Hopper, F., and Brechtel, F.: A case study of gas-to-particle conversion in an eastern Canadian forest, J. Geophys. Res., 104, 8095-8111, 1999.

Marti, J. J., Weber, R. J., McMurry, P. H., Eisele, F., Tanner, D., and Jefferson, A.: New particle formation at a remote continental site: assessing the contributions of $\mathrm{SO}_{2}$ and organic precursors, J. Geophys. Res., 102, 6331-6339, 1997.

Murphy, D. M., Thomson, D. S., and Mahoney, M. J.: In situ measurements of organics, meteoritic material, mercury, and other elements in aerosols at 5 to 19 kilometers, Science, 282, 16641669, 1998.

Novakov, T., Hegg, D. A., and Hobbs, P. V.: Airborne measurements of carbonaceous aerosols on the East Coast of the United States, J. Geophys. Res., 102 (D25), 30 023-30 030, 1997.

Sellegri, K., Laj, P., Peron, F., Dupuy, R., Legrand, M., Preunkert, S., Putaud, J.-P., Cachier, H., and Ghermandi, G.: Mass balance of winter time free tropospheric aerosol at the Puy de Dôme (France), J. Geophys. Res., 108, D11, 4333, doi:10.1029/2002JD002747, 2003.

Sellegri, K., Umann, B., Hanke, M., and Arnold, F.: Deployment of a ground-based CIMS apparatus for the detection of organic gases in the boreal forest during the QUEST campaign, Atmos. Chem. Phys., 5, 357-372, 2005,

\section{SRef-ID: 1680-7324/acp/2005-5-357.}

Spanke, J., Rannik, U., Forkel, R., Nigge, W., and Hoffman, T.: Emission fluxes and atmospheric degradation of monoterpenes above a boreal forest: field measurements and modeling, Tellus, 53B, 406-422, 2001.

Spaulding, R. S., Schade, G. W., Goldstein, A. H., and Charles, M. J.: Characterization of secondary atmospheric photooxidation products: Evidence for biogenic and anthropogenic sources, J. Geophys. Res., 108, D8, doi:10.1029/2002JD002478, 2003.

Spirig, C., Guenther, A., Greenberg, J. P., Calanca, P., and Tarvainen, V.: Tethered balloon measurements of volatile organic compounds at a boreal forest site, Atmos. Chem. Phys., 4, 215 229, 2004,

SRef-ID: 1680-7324/acp/2004-4-215.

Williams, J., Fisher, H., Harris, G. W., Crutzen, P. J., Hoor, P., Hansel, A., Holzinger, R., Warneke, C., Lindinger, W., Scheeren, B., and Lelieveld, J.: Variability-lifetime relationship for organic trace gases: a novel aid to compound identification and estimation of OH concentrations, J. Geophys. Res., 105, 20 473-20 486, 2000.

Yu, J., Cocker III, D. R., Griffin, R. J., Flagan, R. C., and Seinfeld, J. H.: Gas-phase ozone oxidation of monoterpenes: gaseous and particulate products, J. Atmos. Chem., 34, 207-258, 1999. 